\title{
Review \\ Acid Sphingomyelinase Deficiency: Sharing Experience of Disease Monitoring and Severity in France
}

\author{
Wladimir Mauhin ${ }^{1}$, Raphaël Borie ${ }^{2,3}{ }^{1}$, Florence Dalbies ${ }^{4}$, Claire Douillard ${ }^{5}$, Nathalie Guffon ${ }^{6}$, \\ Christian Lavigne ${ }^{7} \mathbb{D}$, Olivier Lidove ${ }^{1, *, \dagger}$ and Anaïs Brassier ${ }^{8, \dagger}$
}

check for updates

Citation: Mauhin, W.; Borie, R.; Dalbies, F.; Douillard, C.; Guffon, N.; Lavigne, C.; Lidove, O.; Brassier, A. Acid Sphingomyelinase Deficiency: Sharing Experience of Disease Monitoring and Severity in France. J. Clin. Med. 2022, 11, 920. https:// doi.org/10.3390/jcm11040920

Academic Editor: Paul L. Huang

Received: 3 December 2021

Accepted: 28 January 2022

Published: 10 February 2022

Publisher's Note: MDPI stays neutral with regard to jurisdictional claims in published maps and institutional affiliations.

Copyright: (C) 2022 by the authors Licensee MDPI, Basel, Switzerland. This article is an open access article distributed under the terms and conditions of the Creative Commons Attribution (CC BY) license (https:// creativecommons.org/licenses/by/ $4.0 /)$
1 Service de Médecine Interne, Centre de Référence Maladies Lysosomales, Groupe Hospitalier Diaconesses Croix Saint-Simon, 75020 Paris, France; WMauhin@hopital-dcss.org

2 Service de Pneumologie A, Hôpital Bichat, 75018 Paris, France; raphael.borie@aphp.fr

3 Unité de Recherche, INSERM, Unité 1152, Université Paris Diderot, 75018 Paris, France

4 Institut de Cancéro-Hématologie, CHU Morvan, 29200 Brest, France; florence.dalbies@chu-brest.fr

5 Centre de Référence des Maladies Héréditaires du Métabolisme, Avenue Avinée, Hôpital Jeanne de Flandres, CHU Lille, 59000 Lille, France; claire.douillard@chu-lille.fr

6 Centre de Référence Lyonnais des Maladies Héréditaires du Métabolisme, Hospices Civils de Lyon, HCL, 69677 Bron, France; nathalie.guffon-fouilhoux@chu-lyon.fr

7 Service de Médecine Interne et Immunologie Clinique, Centre de Compétence des Maladies Métaboliques Héréditaires, CHU Angers, 49933 Angers, France; ChLavigne@chu-angers.fr

8 Service de Pédiatrie et Maladies du Métabolisme, APHP Necker, 75015 Paris, France; anais.brassier@aphp.fr

* Correspondence: OLidove@hopital-dcss.org

$\dagger$ These authors contributed equally to this work.

\begin{abstract}
Acid sphingomyelinase deficiency (ASMD) is a rare inherited lipid storage disorder caused by a deficiency in lysosomal enzyme acid sphingomyelinase which results in the accumulation of sphingomyelin, predominantly within cells of the reticuloendothelial system located in numerous organs, such as the liver, spleen, lungs, and central nervous system. Although all patients with ASMD share the same basic metabolic defect, a wide spectrum of clinical presentations and outcomes are observed, contributing to treatment challenges. While infantile neurovisceral ASMD (also known as Niemann-Pick disease type A) is rapidly progressive and fatal in early childhood, and the more slowly progressive chronic neurovisceral (type A/B) and chronic visceral (type B) forms have varying clinical phenotypes and life expectancy. The prognosis of visceral ASMD is mainly determined by the association of hepatosplenomegaly with secondary thrombocytopenia and lung disease. Early diagnosis and appropriate management are essential to reduce the risk of complications and mortality. The accessibility of the new enzyme replacement therapy olipudase alfa, a recombinant human ASM, has been expedited for clinical use based on positive clinical data in children and adult patients, such as improved respiratory status and reduced spleen volume. The aim of this article is to share the authors experience on monitoring ASMD patients and stratifying the severity of the disease to aid in care decisions.
\end{abstract}

Keywords: acid sphingomyelinase deficiency; ceramide; enzyme replacement therapy; morbidity; mortality; Niemann-Pick disease; olipudase alfa; recombinant human acid sphingomyelinase; sphingomyelin

\section{Introduction}

Acid sphingomyelinase deficiency (ASMD) is an inborn error of metabolism that leads to the accumulation of sphingomyelin in cells and tissues causing the clinical condition also known as Niemann-Pick disease type A, A/B and B (NPD) [1]. In ASMD, the enzymatic deficiency of the lysosomal acid sphingomyelinase (ASM), is caused by pathogenic variants of the sphingomyelin phosphodiesterase 1 gene (SMPD1; EC 3.1.4.12). Sphingomyelin is a major structural component of all plasma membranes. Cellular physiological function requires ASM to catalyze the hydrolysis of sphingomyelin to ceramide and phosphocholine 
(Figure 1). ASMD results in the progressive accumulation of sphingomyelin within all cells, but mainly in reticuloendothelial cells and so in spleen, liver, lung, bone marrow and lymph nodes, but also in neurons in neurovisceral forms. Sphingomyelinase enzyme activity generates ceramides that are bioactive sphingolipids that play a major role in inflammation. Ceramides act as second messengers transducing pro-inflammatory signals such as tumour necrosis factor-alpha [2,3]. Ceramides activate NFkB that in turn encodes for pro-inflammatory cytokines, such as interleukin (IL)-1 beta and IL-6 [4].

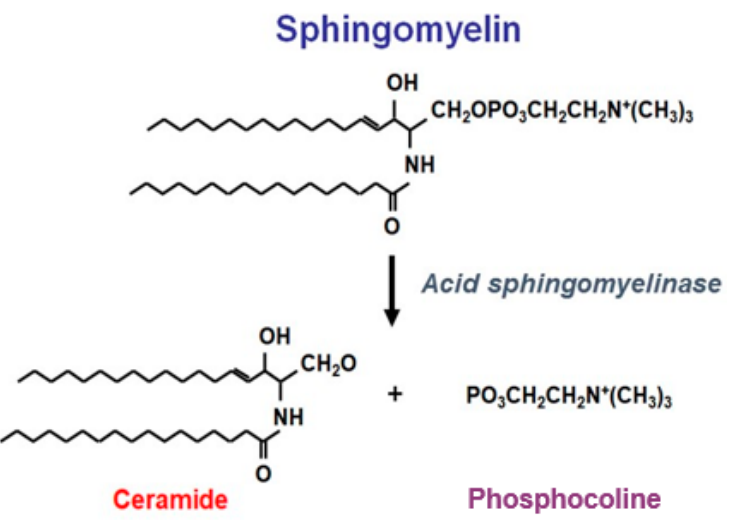

Figure 1. Enzymatic action of acid sphingomyelinase (ASM). Normal physiological function requires ASM to catalyse the hydrolysis of sphingomyelin to ceramide and phosphocoline. Ceramides have a proinflammatory effect as they are bioactive sphingolipids that act as second messengers which transduce pro-inflammatory signals.

Numerous variants of the SMPD1 gene, along with variability in residual ASM activity and other genetic/epigenetic factors, result in a spectrum of ASMD disease severity from a uniformly fatal form with death occurring by 3-4 years of age (ASMD type A or infantile neurovisceral ASMD previously known as NPD A) to chronic forms characterised by visceral (ASMD type B or chronic visceral ASMD, previously NPD B) and neurovisceral disease (ASMD type A/B chronic neurovisceral ASMD, previously NPD A/B) (Table 1) [5-7]. Of note, while Niemann-Pick disease type C and ASMD share several phenotypic features, they represent two distinct disease entities [8]. Reliable estimates of the birth prevalence of ASMD are currently lacking [9]; however, an estimated birth prevalence of $0.4-0.6$ per 100,000 births has been reported [10]. In France, the birth prevalence of the chronic visceral, non-neurological form is $1 / 230,000$ births and is recognised as being an underdiagnosed disease (clinical experience suggests 150 patients diagnosed in France over the last 30 years) [11].

Table 1. Nomenclature for ASMD, adapted from [7].

\begin{tabular}{cc}
\hline Historical Classification & Recommended Nomenclature \\
\hline Niemann-Pick disease type A & Infantile neurovisceral ASMD \\
(NPD A) & (ASMD Type A) \\
Intermediate or variant phenotype & Chronic neurovisceral ASMD \\
(NPD A/B) & (ASMD Type A/B) \\
Niemann-Pick disease type B & Chronic visceral ASMD \\
(NPD B) & (ASMD Type B) \\
\hline
\end{tabular}

ASMD, acid sphingomyelinase deficiency; NPD, Niemann-Pick disease.

The clinical phenotype and life expectancy of patients with ASMD type B appears to vary, with many adults reaching a normal lifespan, while others die prematurely from ASMD-related complications, such as respiratory insufficiency and liver disease [1,5-7,12]. Most patients with ASMD type B have interstitial lung disease with progressive impairment of pulmonary function, hepatosplenomegaly, haematological abnormalities (such as anaemia and thrombocytopenia) with bleeding, and an atherogenic lipid profile [7,9]. 
Diffuse interstitial lung disease with ground glass opacity, interlobular septal thickening, and intralobular lines, is common in ASMD type B [13]; however, symptoms vary from normal function through to respiratory failure $[1,14]$. Other common manifestations include liver disease (from persistent elevated transaminases [5] to cirrhosis [15] with possible liver failure [9]), heart disease (cardiac hypertrophy, valve regurgitation, conduction abnormalities, early myocardial infarction) [14], skeletal abnormalities, failure to thrive, and growth deficits in children which can persist into adulthood [7,16,17].

Data remain limited regarding predictors of disease-related morbidity, healthcare use, and lifestyle impact in patients with chronic ASMD; however, the physical, emotional, financial, and psychosocial burden of illness in patients with ASMD type B and ASMD type A/B is substantial $[1,9,18,19]$. McGovern et al. (2021) reported predictive factors of mortality that include both total splenectomy and spleen volume $\geq 15$ multiples of normal $(\mathrm{MN})$ at baseline [1]. Indeed, in an 11-year prospective natural history study of children and adults with ASMD, patients with a history of either severe splenomegaly or prior splenectomy had 10 times increased the likelihood of dying during follow up compared with those patients with moderate splenomegaly or intact spleens. On the contrary, liver volume of $\geq 2.5 \mathrm{MN}$ was not shown to be a predictor of mortality. Interstitial lung disease was reported to worsen gradually with a mean diffusion capacity of carbon monoxide $\left(\mathrm{DL}_{\mathrm{CO}}\right)$ decreasing below $50 \%$ of the predicted value in adult patients. Atherogenic lipid profiles typically worsen with age in patients with ASMD type B [5], and lipid abnormalities may be associated with early coronary artery disease [20].

Due to the rarity and heterogeneity of the disease, there is a lack of robust quantitative data regarding the impact of the disease on patients' and caregivers' quality of life (QoL), compounded by the lack of adequate disease-specific instruments to measure QoL [9].

\section{Clinical Study Evidence for the Use of Olipudase Alfa in the Non-Neurologic Manifestations of ASMD}

Knockout mouse models have demonstrated that enzyme replacement therapy (ERT) is likely to be a useful therapeutic approach for patients with non-neurological ASMD, with a strong response to ERT in the major organs involved in the disease (liver, spleen, and lung) [21]. For the neurological manifestation of ASMD, ERT is unlikely to evoke any therapeutic response in the central nervous system since it does not cross the bloodbrain barrier. Importantly, progressive dose escalation appeared essential to prevent the possibility of a deadly cytokine storm due to the abrupt release of high levels of ceramide [22].

Olipudase alfa is currently being investigated as an ERT for the treatment of the nonneurological manifestations of ASMD [21,23]. Of note, olipudase alfa is the first and only investigational ERT in late-stage development for ASMD. Olipudase alfa acts by targeting the underlying metabolic defect by supplementing the deficient enzyme activity [24].

A Phase 1A study assessed the infusion of a single dose $(0.03-1.0 \mathrm{mg} / \mathrm{kg})$ of olipudase alfa in 11 patients with ASMD type B [25]; a maximum starting dose of $0.6 \mathrm{mg} / \mathrm{kg}$ was identified which supported a dose-escalation strategy for the gradual clearance of accumulated sphingomyelin which was applied in a Phase 1B study. Of note, the aim of the dose-escalation process of olipudase alfa is gradual sphingomyelin debulking to prevent high ceramide release (Figure 1). Blood ceramide levels increased up to five-fold (both doseand time-dependent), beginning 2-6 h after infusion, peaking between 24 and $48 \mathrm{~h}$ and returning to pre-infusion levels by Day 14 . This led to systemic inflammation illustrated by high levels of $\mathrm{C}$-reactive protein and bilirubin reported in patients who received the highest dosages of olipudase alfa (i.e., 0.6 and $1.0 \mathrm{mg} / \mathrm{kg}$ ). No serious adverse drug reactions occurred during the study.

A Phase 1B study assessed safety and tolerability of olipudase alfa in five patients with ASMD type B reported no death, serious or severe adverse events (AEs), or AEs leading to discontinuation over the 26-week study period [26]; most AEs were mild (97\%) and resolved without sequelae and all patients were successfully escalated to the maximum 
study dose of $3.0 \mathrm{mg} / \mathrm{kg}$. A positive therapeutic response was also observed in liver sphingomyelin content, spleen and liver volumes, along with improvements in infiltrative lung disease, lipid profiles, platelet counts, and QoL. A sustained safety profile and continued improvements in clinically relevant parameters following up to 42 months of treatment in these patients has been reported [26-28].

A long-term safety study (NCT02004704) has demonstrated that olipudase alfa provides improvements in lipid profiles up to 42 months [28-30]; these include progressive reductions from baseline in pro-atherogenic lipid profiles (total cholesterol, low-density lipoprotein cholesterol [LDL-C], very low-density lipoprotein cholesterol, triglycerides) and progressive increases in anti-atherogenic markers (high-density lipoprotein cholesterol and apolipoprotein A-I).

Two separate clinical studies evaluating olipudase alfa for the treatment of chronic ASMD in adult and paediatric patients have also demonstrated positive results [27,31]. The Phase I/II open label, ascending dose, multicentre ASCEND-Peds study (NCT02292654) evaluated the safety, tolerability, and pharmacokinetics of olipudase alfa in 20 paediatric patients with chronic visceral ASMD over a 64-week study period [27]. A clinically meaningful improvement in pulmonary function assessed by the DLco and reduction in spleen size were reported-after 52 weeks of treatment, mean spleen volume decrease was shown to be $49 \%$, while the nine patients who were able to perform the DLco test showed a mean increase of 33\%. Most AEs were mild to moderate in severity, and no permanent treatment discontinuations were reported. The ongoing Phase II/III randomised, double-blind, placebo-controlled ASCEND (adults) study (NCT02004691) evaluated the efficacy, safety, and pharmacokinetics/pharmacodynamics of olipudase alfa in 36 adults with chronic visceral ASMD over a 52-week primary analysis period, which is now being followed by an extension period (all treated patients) of up to 4 years [31]. Patients received either olipudase alfa intravenous infusion or placebo every two weeks at an escalating dose from $0.1 \mathrm{mg} / \mathrm{kg}$ up to $3 \mathrm{mg} / \mathrm{kg}$ administered every two weeks. Figure 2 shows the dose-escalation strategy used in the ASCEND (adults) and ASCEND-Peds studies. The ASCEND (adults) study assessed two independent primary efficacy endpoints: DLco and spleen volume to reflect the separate critical manifestations of chronic visceral ASMD, with the trial outcome being deemed positive if one of these endpoints was met. Treatment outcomes favoured olipudase alfa (vs placebo) at Week 52 for spleen volume, percentage predicted DLco, liver volume and platelet levels. Overall, spleen volume was significantly decreased by $39.5 \%$ in the olipudase alfa arm compared with a $0.5 \%$ increase in the placebo arm $(40 \%$ difference; $p<0.0001)$. In addition, percent change from baseline in percentage predicted DLco was $+22 \%$ for the olipudase alfa arm at Week 52 compared with $+3 \%$ for the placebo arm (19\% difference; $p=0.0004)$. In addition, all treatment-related AEs were mild-to-moderate in severity and no patients discontinued due to AEs [19].

In 2015, the US Food and Drug Administration granted a breakthrough therapy designation to olipudase alfa based on the Phase $1 \mathrm{~b}$ study data, an approach used to expedite the development and review of drugs intended to treat serious or life-threatening diseases and conditions [32]. Similarly, in 2016, olipudase alfa has gained orphan designation and 'PRIority Medicines' (PRIME) designation by the European Medicines Agency, along with being awarded the SAKIGAKE designation in Japan, in order to expedite the regulatory process [33]. 


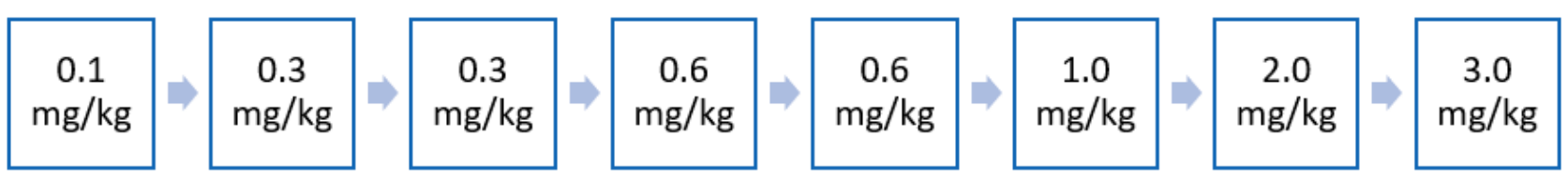

(A)

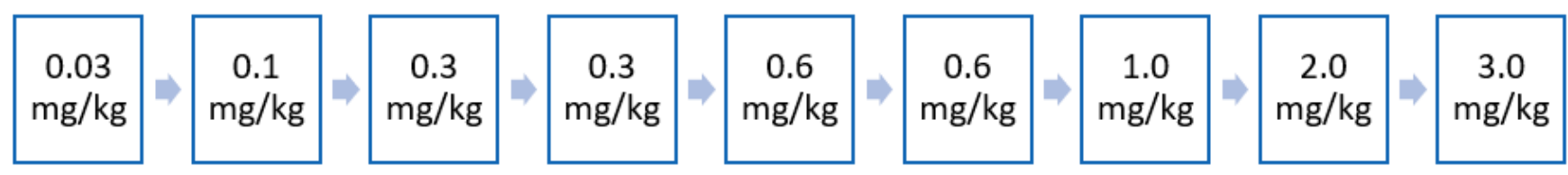

(B)

Figure 2. (A) Dose escalation regimen for adult patients administered every 2 weeks. Dose-escalation strategy for olipudase alfa after the Phase 1B study [31]. The aim of the dose-escalation process of olipudase alfa is gradual sphingomyelin debulking to prevent high ceramide release. BMI, body mass index. (B) Dose escalation regimen for pediatric patients administered every 2 weeks. Dose escalation regimen of olipudase alfa phase I/II ASCEND PEDS [27].

\section{Materials and Methods}

Four expert meetings took place in Paris from 2019 to 2021, followed by several teleconferences, to gather expert opinion of French physicians with regards to the monitoring and severity stratification of children and adult patients with ASMD types B and A/B. All authors participated in the meetings apart from W.M. W.M., O.L., and A.B. have coordinated the process of early access to treatment in French ASMD patients. All co-authors have worked on this process.

\section{French Expert Opinion: Monitoring of ASMD and Patient Severity Stratification \\ 4.1. General Care of Patients with ASMD Type B Forms}

Treatment goals for patients with chronic visceral ASMD should focus on reducing spleen and liver volumes, limiting hepatic fibrosis, decreasing cytopenia, improving liver function tests, and respiratory status in order to decrease morbidity and mortality [12]. However, the current management of ASMD type B has been limited to supportive care and palliation $[9,13,34]$.

Regardless of aetiology, any respiratory failure should be treated with oxygen and respiratory rehabilitation $[9,35,36]$. Patients should also be encouraged to stop or avoid smoking (including second-hand exposure), to reduce the risk of lung and coronary disease, as well as cancer $[13,37]$. There is no specific recommendation but standard lipid-lowering agents, such as statins or ezetimibe, have shown benefits and are classically proposed to manage blood lipid abnormalities $[9,13,38]$.

While there is no available treatment shown to improve bone density in patients with ASMD type B, the use of regular calcium and vitamin D supplementation to support healthy bone function is recommended [9]; of note, the use of bisphosphonates should be avoided given their potent inhibition of ASM [39].

Due to the low platelet count and splenomegaly, contact sports (particularly those with a risk of abdominal impact) should be avoided [9]. Splenectomy should be avoided as it has been demonstrated to increase the risk of lung disease and overall mortality [5].

Optimised immunisation in ASMD patient population is challenging because of a data gap in vaccine trials. Vaccinations against pneumococci, Haemophilus influenzae type $\mathrm{B}$, meningococci, and influenza virus are recommended for patients with anatomic or functional asplenia $[9,13,40]$. While the use of the meningitis vaccine is mandatory in paediatric patients, its use in adult patients is also mandatory in patients with anatomic or functional asplenia [41]. In adult patients with platelets $>30 \mathrm{G} / \mathrm{L}$, vaccination against 
COVID-19 should now empirically be offered, as with all patients with a higher risk of severe COVID-19 due to chronic lung and/or liver disease [42].

\subsection{Monitoring of Patients with ASMD Type B Forms}

Scheduled patient monitoring remains essential to manage symptoms as early as possible, in order to minimise the risk of poor clinical outcomes. Based on our experience, a summary of key monitoring parameters along with the frequency of assessment for patients with ASMD type B are shown in Table 2 (pulmonary, hepato-splenic, and haematological assessments) and Table 3 (summary of all monitoring parameters). It is recommended that patient monitoring would be undertaken by a multidisciplinary team in an experienced centre (referral or competence centre in France). As with other diseases, the frequency of monitoring must be determined by patient severity and assessment results, as well as the progression of the disease.

Given the future availability of ERT, there is a need for biomarkers that predict or reflect disease progression [17]; suitable markers need to be validated for their use as surrogate markers of clinically relevant endpoints. Eskes et al. (2020) highlighted that the best evaluated potential biomarkers for ASMD are DLco, spleen volume, platelet count, LDL-C, liver fibrosis (measured with fibroscan) and lysosphingomyelin [17]. Our opinion is that the biomarkers chitotriosidase, lysosphingomyelin, and lysosphingomyelin 509 should be assessed at baseline, with follow up every 3 or 6 months for the first year, and then every year (Table 3).

Given that ASMD is an autosomal recessive inherited condition, carrier testing for at-risk relatives, prenatal testing for a pregnancy at increased risk, and preimplantation genetic testing are all possible, following the identification of a SMPD1 pathogenic variant in an affected family member $[43,44]$. In general, there is no specific complication during pregnancy in patients with ASMD type B; although, episodes of bleeding have been reported. ASMD type $A$ is the most severe form of ASMD with rapidly progressive neurovisceral manifestations and fatal issues with multisystem involvement. For ASMD type A, prenatal diagnosis is routinely accomplished by mutational analysis when an index case is identified in the family [43].

Table 2. Key monitoring parameters and frequency of assessments for patients with ASMD type B forms.

\begin{tabular}{|c|c|c|c|c|}
\hline Exam & $\begin{array}{c}\text { Baseline } \\
\text { Visit }\end{array}$ & $\begin{array}{l}\text { Follow-Up Visit in } \\
\text { the First } 6 \text { Months }\end{array}$ & $\begin{array}{l}\text { Follow-Up Visit Every } \\
3 \text { Months for the First Year }\end{array}$ & $\begin{array}{c}\text { Follow-Up Visit } \\
\text { Every Year }\end{array}$ \\
\hline $\begin{array}{l}\text { Pulmonary assessment } \\
\text { Respiratory functional exploration } \\
\text { (DLco-not before } 6 \text { years) } \\
\text { CT: thoracic }\end{array}$ & $\begin{array}{l}X \\
X\end{array}$ & $X$ & & $\begin{array}{c}X \\
X^{a}\end{array}$ \\
\hline $\begin{array}{c}\text { Hepato-splenic } \\
\text { assessment } \\
\text { Splenic and hepatic volume (ultrasound } \\
+/- \text { abdominal MRI in adults; } \\
\text { ultrasound in children) } \\
\text { Portal hypertension (abdominal } \\
\text { ultrasound with Doppler) }\end{array}$ & $X$ & $x$ & & $X$ \\
\hline $\begin{array}{c}\text { Transaminases, } \\
\text { alkaline phosphatase, bilirubin } \\
\text { Haematological } \\
\text { assessment } \\
\text { CBC, platelets, haemostasis assessment } \\
\text { (PT, factor V, fibrin, APTT, ferritin) } \\
\text { Lipid blood-test } \\
\text { including total, LDL and HDL }\end{array}$ & $x$ & $X$ & $\begin{array}{l}X \\
X\end{array}$ & $X$ \\
\hline
\end{tabular}

a If normal, then every 5 years. APTT, activated partial thromboplastin time; CBC, complete blood count; CT, computed tomography; DLco, diffusing capacity of the lungs for carbon monoxide; HDL, high density lipoprotein, LDL, low density lipoprotein; MRI, magnetic resonance imaging; PT, prothrombin time. 
Table 3. Key monitoring parameters and frequency of assessment for patients with ASMD type B forms (NPD B).

\begin{tabular}{c}
\hline Test \\
\hline Lung assessment \\
PFT \\
Blood gases \\
CT scan \\
$\begin{array}{r}\text { At baseline visit and at follow-up visit annually, unless } \\
\text { normal (then assess every } 5 \text { years) }\end{array}$
\end{tabular}

PFT possible in children from 5-6 years

Need to monitor DLco (annually or at clinician's discretion) following olipudase alfa treatment initiation

Non-predictive test

Not routinely recommended, especially in children, and depending on symptomatology in adults

Radiation examination in a population at risk of cancer In paediatric patients $<4-5$ years, sedation or general anaesthesia is required (depending on the child's behaviour)

\begin{tabular}{|c|c|c|}
\hline $\begin{array}{l}\text { Hepato-splenic } \\
\text { assessment }\end{array}$ & & \\
\hline Liver blood tests & $\begin{array}{l}\text { At baseline visit, at follow-up visit in first } 6 \text { months, } \\
\text { and at follow-up visit annually }\end{array}$ & $\begin{array}{l}\text { Assess GGT, transaminases, ALP, } \\
\text { bilirubin, PT, CRP, Factor V }\end{array}$ \\
\hline $\begin{array}{l}\text { Abdominal ultrasound with } \\
\text { doppler }\end{array}$ & $\begin{array}{l}\text { At baseline visit, at follow-up visit in first } 6 \text { months, } \\
\text { and at follow-up visit annually }\end{array}$ & $\begin{array}{c}\text { Early detection of steatosis, PHT, cirrhosis or nodule } \\
\text { Possible in children }<5 \text { years of age }\end{array}$ \\
\hline $\begin{array}{l}\text { Abdominal MRI } \\
\text { (adult patients) }\end{array}$ & At initial assessment and then every 2 years & $\begin{array}{l}\text { Higher sensitivity for nodule detection } \\
\text { Possible in children }>5 \text { years of age }\end{array}$ \\
\hline Fibroscan & - & Not recommended as not validated for ASMD \\
\hline Liver biopsy & To consider if hepatocarcinoma is suspected & $\begin{array}{l}\text { No correlation with biological tests (transaminases } \\
\text { usually }<5 \mathrm{~N} \text { ). Characterisation of nodule may require } \\
\text { alpha-foetoprotein, liver ultrasound, and MRI }\end{array}$ \\
\hline Alpha-fetoprotein & - & No recommendation for systematic assessment \\
\hline \multicolumn{3}{|l|}{$\begin{array}{l}\text { Haematological } \\
\text { assessment }\end{array}$} \\
\hline $\begin{array}{l}\text { CBC, platelets, haemostasis } \\
\text { test (PT, Factor V, fibrin, } \\
\text { aPTT), ferritin }\end{array}$ & $\begin{array}{c}\text { Assessment at baseline visit, at follow-up visit every } 3 \\
\text { months during first year, and at follow-up visit } \\
\text { annually }\end{array}$ & - \\
\hline Protein electrophoresis & At initial assessment and then annually & $\begin{array}{l}\text { Risk of hyper or hypogammaglobulinemia and risk } \\
\text { of MGUS } \\
\text { No need to perform any immunoelectrophoresis }\end{array}$ \\
\hline Serum albumin & $\begin{array}{l}\text { At initial assessment then every } 2-3 \text { years if the initial } \\
\text { assay is normal }\end{array}$ & - \\
\hline \multicolumn{3}{|l|}{$\begin{array}{l}\text { Bone assessment and } \\
\text { growth evaluation }\end{array}$} \\
\hline Growth curve & $\begin{array}{l}\text { Assessment at baseline visit and at follow-up visit } \\
\text { every } 6 \text { months }\end{array}$ & - \\
\hline Phosphocalcium balance & $\begin{array}{l}\text { Assessment at baseline visit and at follow-up visit } \\
\text { every } 6 \text { months }\end{array}$ & $\begin{array}{l}\text { Assessment to include blood calcium and phosphorus, } \\
\text { vitamin D, creatinine, proteinuria, urine calcium and } \\
\text { sodium, and creatininuria } \\
\text { Patients are at risk of cholestasis }\end{array}$ \\
\hline Absorptiometry & $\begin{array}{c}\text { Assessment at baseline visit and then every } 5 \text { years if } \\
\text { normal or every } 3 \text { years if anormal }\end{array}$ & Possible in children aged from 5-6 years old \\
\hline Resorption markers & Optional & To be performed if osteoporosis is known \\
\hline \multicolumn{3}{|l|}{$\begin{array}{l}\text { Cardiovascular assessment } \\
\text { and lipid profile }\end{array}$} \\
\hline Echocardiography & At initial assessment and then every 2 years & \\
\hline $\begin{array}{l}\text { Coronary computed } \\
\text { tomographic angiography }\end{array}$ & $\begin{array}{c}\text { Discuss coronary computed tomographic angiography } \\
\text { depending on lipid profile and other cardiovascular } \\
\text { risk factors }\end{array}$ & No monitoring data in ASMD type B disease \\
\hline Lipid profile & $\begin{array}{c}\text { Assessment at baseline visit, at follow-up visit every } \\
3 \text { months during first year, and at follow-up } \\
\text { visit annually }\end{array}$ & Unproven benefit of statins in primary prevention \\
\hline
\end{tabular}


Table 3. Cont.

\begin{tabular}{cc}
\hline Test & Monitoring Frequency \\
\hline $\begin{array}{c}\text { Neurological assessment }{ }^{\text {a }} \\
\text { Peripheral }\end{array}$ & Monitoring frequency: at initial assessment and then annually \\
\hline Clinical examination & Monitoring frequency: to be considered if there are clinical call points \\
\hline EMG & Monitoring frequency in adults: to be considered at initial assessment according to the clinical context and the \\
neuropsychological tests \\
Brain MRI
\end{tabular}

Ophthalmic assessment

\begin{tabular}{ccc}
\hline Ocular fundus & At initial assessment & $\begin{array}{c}\text { The macular cherry-red spot is present in all patients } \\
\text { with form A, and has been reported in one third of } \\
\text { patients with form B [20] }\end{array}$ \\
\hline Visual acuity & At initial assessment & $\begin{array}{c}\text { Loss of visual acuity in infantile type (no effect in } \\
\text { chronic visceral ASMD) }\end{array}$
\end{tabular}

\begin{tabular}{|c|c|c|}
\hline \multicolumn{3}{|l|}{ Other } \\
\hline Dermatological examination & At initial assessment and then annually & $\begin{array}{l}\text { Necessary in order to assess the presence of } \\
\text { lymphoedema (eyelid infiltration) }\end{array}$ \\
\hline $\begin{array}{l}\text { TSH assay (in combination } \\
\text { with anti-TPO antibodies) }\end{array}$ & At initial assessment and then annually & $\begin{array}{l}\text { Necessary for the investigation of thyroid } \\
\text { autoimmunity }\end{array}$ \\
\hline \multicolumn{3}{|l|}{ Biomarkers } \\
\hline \multirow[t]{2}{*}{ Chitotriosidase } & $\begin{array}{c}\text { At initial assessment, follow-up every } 3 \text { months for the } \\
\text { first year, and then every year }\end{array}$ & $\begin{array}{l}\text { Chitotriosidase activity is absent in } 6-8 \% \text { of individuals } \\
\text { in the general population }\end{array}$ \\
\hline & & Specialised assays, contact reference laboratories \\
\hline \multirow[t]{2}{*}{$\begin{array}{l}\text { Lysosphingomyelin } \\
+ \text { Lysosphingomyelin } \\
\text { isoform } 509\end{array}$} & $\begin{array}{c}\text { At initial assessment, follow-up every } 3 \text { months for the } \\
\text { first year, and then every year }\end{array}$ & Specialised assays, contact reference laboratories \\
\hline & $\begin{array}{l}\text { a Note: The clinical dichotomy between forms A a } \\
3-6 \text { months). For form A/B, the age of onset of neu } \\
\text { variable age, possible after the age of } 3 \text { years). aPTT, a } \\
\text { count; CRP, C-reactive protein; CT, computerised ton } \\
\text { monoxide; EMG, electromyography; GGT, gamma-g } \\
\text { unknown significance; MRI, magnetic resonance imagi } \\
\text { PT, prothrombin time; TSH, thyroid-stimulating horn }\end{array}$ & $\begin{array}{l}\text { d B occurs very early before the age of } 1 \text { year (around } \\
\text { logical signs is highly variable (delayed acquisition at a } \\
\text { tivated partial thromboplastin time; CBC, complete blood } \\
\text { graphy; DLco, diffusing capacity of the lungs for carbon } \\
\text { utamyl transferase; MGUS, monoclonal gammopathy of } \\
\text { g; PFT, pulmonary function test; PHT, portal hypertension; } \\
\text { one; TPO, thyroid peroxidase. }\end{array}$ \\
\hline
\end{tabular}

\subsection{Patients with ASMD: Stratification by Disease Severity}

In France, the exceptional use of proprietary medicinal products which do not have a marketing authorisation and are not the subject of a clinical trial can occur under the following three conditions: (1) specialties are intended to treat, prevent, or diagnose serious or rare diseases; (2) there is no appropriate treatment available on the market; and (3) their efficacy and safety of use are presumed in the state of scientific knowledge and the implementation of the treatment cannot be postponed [45]. This exceptional so-called 'Temporary Use Authorisation' (TUA) is delineated by specific criteria that have to be defined according to the results of the different trials and the criteria of the expected future marketing authorisation.

Where treatment is warranted based on disease severity, early access to olipudase alfa can be possible based on the following conditions: (1) the patient or person of trust must be informed of the exceptional and critical nature of this requirement; (2) specialties are intended to treat, prevent, or diagnose serious or rare diseases; (3) there is no appropriate treatment available on the market; (4) the patient cannot be included in a clinical trial; and (5) the effectiveness and safety of use of the prescribed treatment are not only presumed in the state of scientific knowledge and the implementation of the processing cannot be postponed. 
In order to define the access criteria to the TUA procedure, the Therapeutic Evaluation Committee for Visceral Lipidoses (CETLv) in France convened a disease severity classification of patients with ASMD type B or A/B, i.e., via the Brassier-Lidove classification (Table 4). Worsening dyspnoea, low platelets $<50 \mathrm{G} / \mathrm{L}$ and/or recurrent bleeding, biological and/or histological liver damage, and painful splenomegaly are key features of severe disease. Important clinical criteria in paediatric patients include a break in the growth curve or painful splenomegaly (Figure 3).

Table 4. Patients with chronic ASMD grouped among disease severity (CETLv classification).

\begin{tabular}{cc}
\hline Group & Definition \\
\hline $\begin{array}{c}\text { Group outside the early access } \\
\text { spectrum application }\end{array}$ & $\begin{array}{c}\text { ASMD types B and A/B (NPD B or A/B) with a } \\
\text { short-term vital prognosis (e.g., cancer) }\end{array}$ \\
& DLco $^{\mathrm{a}}<50 \%$ and / or dyspnoea \\
$\begin{array}{c}\text { Group 1: Patients with severe } \\
\text { organ involvement }\end{array}$ & $\begin{array}{c}\text { Platelets }<50 \mathrm{G} / \mathrm{L} \pm \text { recurrent bleeding or bruising } \\
\text { Abdominal pain }\end{array}$ \\
& Urgent need to start treatment \\
& Break in growth curve ( $\geq 2$ standard deviation) \\
\hline
\end{tabular}

Group 2: Patients in therapeutic trials organ involvement

Group 4: Patients with mild organ
involvement

Group 5: Patients with no symptoms
Patient continues to receive treatment as part of clinical trial or extension study

$50 \%<$ DLco $<70 \%$

$50 \mathrm{G} / \mathrm{L}<$ Platelets $<100 \mathrm{G} / \mathrm{L}$ without bleeding or bruising

Failure to thrive/break in growth curve ( $>1$ standard deviation)

DLco $>70 \%$

Platelets $>100 \mathrm{G} / \mathrm{L}$

Abnormal thoracic imagery and/or hepatosplenomegaly

$\mathrm{DL}_{\mathrm{CO}}>70 \%$

Platelets $>100 \mathrm{G} / \mathrm{L}$

No symptom

Normal thoracic imagery

No hepato-splenomegaly

ASMD, acid sphingomyelinase deficiency; DLco, diffusing capacity of the lungs for carbon monoxide; NPD, Niemann-Pick disease. ${ }^{\text {a }}$ DLco not available for patients aged $<6$ years old.
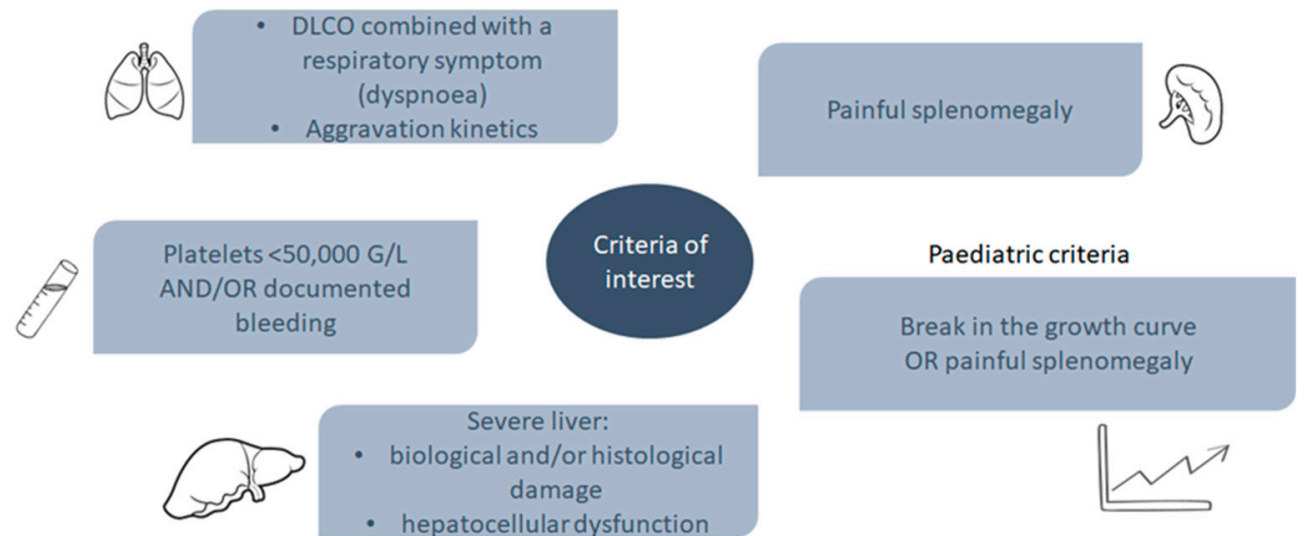

Figure 3. Clinical criteria of interest for patients with ASMD type B or A/B. ASMD, acid sphingomyelinase deficiency; DLco, diffusing capacity of the lungs for carbon monoxide.

During nominative early access to olipudase alfa the Brassier-Lidove classification (CETLv classification) (Table 4) has been applied. Of 29 adult patients from the Croix Saint-Simon Hospital (Paris, France), two were deemed to be outside the early access application because of a limited life expectancy, two were in CETLv Group 1 and were too 
severely affected to participate in ASCEND trial (Table 5) (one patient with symptomatic thrombocytopenia $<40 \mathrm{G} / \mathrm{L}$ and one patient with severe pulmonary failure awaiting lung transplantation), two were in CETLv Group 2 (both patients were participating in the ASCEND study), eight patients were in CETLv Group 3 (including two patients receiving psychotropic drugs), ten patients were in CETLv Group 4, and five patients in CETLv Group 5. Of this patient cohort, 10/29 (34.5\%) patients were deemed to be eligible for olipudase alfa via ATU according to the CETLv classification. In the Referral Center for Inherited Diseases of Metabolism at the Hospices Civils of Lyon (Lyon, France), there have been two children treated since 2015 and 2018 as part of the pediatric clinical trial and two children treated as part of a nominative ATU (Group 1). Two adults have also been treated in the ATU for severe lung damage (Group 1).

Table 5. Criteria in ASCEND (adults and peds) study for use of olipudase alfa.

\begin{tabular}{|c|c|c|}
\hline Criteria & ASCEND (Adults) & ASCEND Peds \\
\hline Lung & $\begin{array}{l}\text { Inclusion criteria: } \\
-\quad \text { DLco } \leq 70 \% \\
\text { Exclusion criteria: } \\
\text { - } \quad \text { Invasive ventilation } \\
\text { - Non-invasive ventilation }>12 \mathrm{~h} / \text { day }\end{array}$ & $\begin{array}{l}\text { Exclusion criteria: } \\
\bullet \quad \text { Invasive ventilation } \\
-\quad \text { Non-invasive ventilation }>12 \mathrm{~h} / \text { day }\end{array}$ \\
\hline Spleen & $\begin{array}{l}\text { Inclusion criteria: } \\
\text { - Spleen volume } \geq 6 \mathrm{MN} \text {, measured by MRI; } \\
\text { patients who have had a partial splenectomy } \\
\text { may be included if the procedure was } \\
\text { performed } \geq 1 \text { year prior to screening and the } \\
\text { residual spleen volume is } \geq 6 \mathrm{MN} \\
\text { - SRS score } \geq 5 \text { over one week }\end{array}$ & $\begin{array}{l}\text { Inclusion criteria: } \\
\text { - Spleen volume } \geq 5 \text { multiples of normal (MN), } \\
\text { measured by MRI; patients who have had a } \\
\text { partial splenectomy may be included if the } \\
\text { procedure was performed } \geq 1 \text { year prior to } \\
\text { screening and the residual spleen volume } \\
\text { is } \geq 5 \mathrm{MN}\end{array}$ \\
\hline Liver & $\begin{array}{l}\text { Exclusion criteria: } \\
\text { - } \quad \text { Active hepatitis B or hepatitis C } \\
\text { ALT or AST }>250 \text { IU / L or total bilirubin > }>1.5 \\
\text { mg/dL (except for patients with Gilbert's } \\
\text { syndrome) } \\
\text { Major organ transplantation (liver, bone } \\
\text { marrow) } \\
\text { The patient is unwilling or unable to refrain } \\
\text { from taking any potentially hepatotoxic } \\
\text { medication or herbal supplement } 10 \text { days } \\
\text { before and } 3 \text { days after the liver biopsies }\end{array}$ & $\begin{array}{l}\text { Exclusion criteria: } \\
\text { - } \quad \text { Active hepatitis B or hepatitis C } \\
\text { - } \quad \text { Cirrhosis (determined by clinical assessment) } \\
\text { - } \quad \text { Major organ transplantation (liver, bone } \\
\text { marrow) } \\
\text { - } \quad \text { ALT or AST }>250 \mathrm{IU} / \mathrm{L} \text { or total } \\
\text { bilirubin }>1.5 \mathrm{mg} / \mathrm{dL}\end{array}$ \\
\hline Blood & $\begin{array}{l}\text { Exclusion criteria: } \\
\text { Platelet count }<60 \mathrm{G} / \mathrm{L} \\
\text { INR > } 1.5 \\
\text { The patient is unwilling or unable to avoid } \\
\text { taking any medication or herbal supplements } \\
\text { that may cause or prolong bleeding, } 10 \text { days } \\
\text { before and } 3 \text { days after the liver biopsies }\end{array}$ & $\begin{array}{l}\text { Exclusion criteria: } \\
\text { - } \quad \text { Platelet count }<60 \mathrm{G} / \mathrm{L} \\
\text { - } \quad \text { INR }>1.5\end{array}$ \\
\hline $\begin{array}{l}\text { Bone/growth } \\
\text { retardationBone } \\
\text { damageDelayed } \\
\text { growth }\end{array}$ & $\begin{array}{l}\text { - } \quad \text { No mention of bone criteria } \\
\text { Inclusion criteria: } \\
\text { - } \quad \text { Size of }-1 \text { Z-score or lower }\end{array}$ & - No mention of bone criteria \\
\hline $\begin{array}{l}\text { Central nervous } \\
\text { system }\end{array}$ & - No mention of criteria & $\begin{array}{l}\text { Exclusion criteria: } \\
\text { - } \quad \text { Acute or rapidly progressive neurological } \\
\text { abnormality } \\
\text { - Homozygosity for the R496L, L302P, and fs330 } \\
\text { mutations or any combination of these } \\
3 \text { mutations } \\
\text { - Delayed motor skills }\end{array}$ \\
\hline
\end{tabular}


Table 5. Cont.

\begin{tabular}{|c|c|c|}
\hline Criteria & ASCEND (Adults) & ASCEND Peds \\
\hline Cardiovascular & $\begin{array}{l}\text { Exclusion criteria: } \\
\text { - } \quad \text { Significant heart disease } \\
\text { Major organ transplantation (liver, bone } \\
\text { marrow) } \\
\text { No mention of dyslipidaemia/coronary } \\
\text { calcifications }\end{array}$ & $\begin{array}{l}\text { Exclusion criteria: } \\
\text { - } \quad \text { Significant heart disease } \\
\text { - No mention of dyslipidaemia/coronary } \\
\text { calcifications }\end{array}$ \\
\hline Pain/fatigue & $\begin{array}{l}\text { Inclusion criteria: } \\
\text { - } \quad \text { SRS score } \geq 5\end{array}$ & No mention of specific criteria \\
\hline \multicolumn{3}{|c|}{$\begin{array}{l}\text { ALT, alanine aminotransferase; AST, aspartate transaminase; DLco, diffusing capacity of the lung; INR, inter- } \\
\text { national normalised ratio; MN, multiples of normal; MRI, magnetic resonance imaging. SRS (Splenomegaly } \\
\text { Related Symptom) score: a score composed of } 5 \text { items (abdominal pain, abdominal discomfort, early satiety, } \\
\text { self-image, ability to stoop). This score is derived from the Myeloproliferative Syndrome Assessment Score } \\
\text { (MF-SAF) (JAKARTA, NCT\# 01437787). The questions assess the effect over the last } 24 \text { h of the splenomegaly in } \\
\text { patients with NPB disease. }\end{array}$} \\
\hline
\end{tabular}

\section{Early Access Experience to ERT in France}

Prior to full marketing authorisation, as of 14 October 2021, compassionate use of olipudase alfa was initiated in France in 4 nominative pediatric patients and 19 adult patients. A total of 14 physicians originating from 12 different cities (Lyon, ClermontFerrand, Bordeaux, Angers, Paris, Marseille, Quimper, Clichy, Strasbourg, Lille, Toulouse, and Caen) are currently treating ASMD patients, at the rate of about 1 to 5 patients per center. Of note, 16 out of these 23 patients were initiated with olipudase alfa by the co-authors of this work. Dose escalation (Figure 2) was conscientiously followed.

\section{Discussion}

In ASMD, as the lysosomal sphingomyelinase enzymatic defect is expressed ubiquitously throughout the organs, improvement in one tissue may be considered as representative of an overall improvement in non-neurological clinical status.

Available evidence from the natural history of ASMD and observational studies support the use of DLco and splenomegaly as clinically meaningful endpoints that assess disease burden for patients. Worsening DLco is a strong indicator of progressive lung disease in chronic visceral ASMD, contributing to increased disease burden. Likewise, spleen volume may be considered as a surrogate marker for bleeding risk and liver disease. Pneumonia/respiratory failure, and/or liver failure, are often the causes of death [9].

The main clinical criteria that were considered in France to prioritise early access to treatment with olipudase alfa in patients with ASMD type B or type A/B are low DLco with worsening dyspnoea, thrombocytopenia $<50 \mathrm{G} / \mathrm{L}$ or recurrent bleeding, biological and/or histological liver damage, and painful splenomegaly (Figure 3), and in the case of paediatric patients a break in the growth curve or painful splenomegaly should be considered (Figure 3). Thus, a complete evaluation of the patient prior treatment initiation is mandatory in order to assess the potential benefit of olipudase alfa on the spleen volume, respiratory function, and platelet count, as well as any possible issues related to tolerance and comorbidities, such as tobacco use. In addition, as lung, spleen, liver, platelet status, and growth curve can worsen, a regular follow up with clinical, biological, and morphological of pauci/asymptomatic patients must be performed. The CETLv stratification of severity may aid the physician in health care decisions.

Data from the ASCEND (adult) and ASCEND-Peds (paediatric) studies have demonstrated that olipudase alfa can improve respiratory status and reduce spleen volume in patients with visceral ASMD (Table 5) [27,31]. In addition, the clinical relevance of the endpoints used in these studies is well documented [46]. Of note, patients included in the ASCEND (adult) and ASCEND-Peds studies did not exhibit the full spectrum of severity in patients with ASMD, excluding asymptomatic individuals and those with very severe disease. After dose escalation, steady-state dose infusions, and record of adequate tolerance to 
olipudase alfa, home therapy with a multidisciplinary team and regular follow-up should be considered. An 'emergency card' delivered to the patient could be helpful to improve the communication between the patient, and home and hospital caregivers in patients in home infusion.

The present early experience can be used as the basis for further clinical evaluations.

\section{Conclusions}

The management of chronic visceral and ASMD type B and A/B has traditionally been limited to supportive care and palliation. Clinical studies in patients with chronic ASMD have demonstrated positive results with the novel ERT olipudase alfa, comprising improvement in respiratory status and spleen volume reduction, as well as improvement in other clinical manifestations. In France, low DLco with worsening dyspnoea, thrombocytopenia $<50 \mathrm{G} / \mathrm{L}$ or recurrent bleeding, biological and/or histological liver damage, and painful splenomegaly have been used to prioritise early compassionate use of olipudase alfa in nominative paediatric and adult patients with ASMD. Of note, the use of any decisionmaking process/stratification for patients with ASMD need to be confirmed by 'real-life' evidence. In addition, scheduled follow up of treated patients outside clinical trials is mandatory to assess the effect of olipudase alfa in those individuals with chronic ASMD. Regular follow up must be performed in untreated patients with ASMD. Asymptomatic patients should be evaluated by experts on a 'case-by-case' basis to ensure opportune early treatment initiation.

Author Contributions: The study was conceived and designed by W.M., O.L. and A.B. All authors were responsible for the acquisition of data. Analysis of data, drafting, and writing of the manuscript was undertaken by W.M., O.L. and A.B. All authors have read and agreed to the published version of the manuscript.

Funding: Third-party medical writing support for this manuscript was funded by Sanofi Genzyme.

Institutional Review Board Statement: Not applicable.

Informed Consent Statement: Not applicable.

Data Availability Statement: Not applicable.

Acknowledgments: Third-party medical writing support was provided by Matthew Joynson of Springer Healthcare Ltd. We would like to acknowledge M.T. Vanier, T. Levade, and R. Froissart who have performed the majority of diagnoses of ASMD in France over the last 30 years. In addition, we would like to thank patients and families, French patient association Vaincre les Maladies Lysosomales (VML, www.vml-asso.org, accessed on 30 November 2021), the Reference Center for Lysosomal Diseases (CRML), the members of the CETLv, the co-workers of the Groupe collaboratif français, and other collaborators (physicians, biochemists, geneticists, pharmacists, and other supporting disciplines).

Conflicts of Interest: Wladimir Mauhin declares honoraria and travel hospitality from SanofiGenzyme, Shire-Takeda, Chiesi and Amicus Therapeutics. Raphaël Borie received honoraria from Sanofi Genzyme, Roche and Boehringer. Florence Dalbies has received travel grants and speaker honoraria from Sanofi Genzyme. Claire Douillard has received travel grants honoraria from Sanofi Genzyme, Biomarin, Ultragenyx, Shire. Nathalie Guffon is involved as a Principal Investigator into ASCEND Peds clinical trials a Sanofi Genzyme sponsored trial and received some grants/fees from Sanofi Genzyme, Ultragenyx, Takeda, BioMarin. Christian Lavigne has received travel grants honoraria and speaker honoraria from Sanofi Genzyme, Swedish Orphan Biovitrum, Ultragenyx, Shire and Biomarin. Olivier Lidove is principal investigator in ASCEND, a Sanofi-Genzyme sponsored trial, and has received travel grants and speaker honoraria from Amicus and Sanofi Genzyme. Anaïs Brassier has received travel grants and speaker honoraria from Sanofi Genzyme, Shire HGT, Orchard therapeutics, Biomarin, and Alexion. 


\section{References}

1. McGovern, M.M.; Wasserstein, M.P.; Bembi, B.; Giugliani, R.; Mengel, K.E.; Vanier, M.T.; Zhang, Q.; Peterschmitt, M.J. Prospective study of the natural history of chronic acid sphingomyelinase deficiency in children and adults: Eleven years of observation. Orphanet J. Rare Dis. 2021, 16, 212. [CrossRef] [PubMed]

2. Mathias, S.; Dressler, K.A.; Kolesnick, R.N. Characterization of a ceramide-activated protein kinase: Stimulation by tumor necrosis factor alpha. Proc. Natl. Acad. Sci. USA 1991, 88, 10009-10013. [CrossRef] [PubMed]

3. Albeituni, S.; Stiban, J. Roles of ceramides and other sphingolipids in immune cell function and inflammation. Adv. Exp. Med. Biol. 2019, 1161, 169-191. [PubMed]

4. Schütze, S.; Potthoff, K.; Machleidt, T.; Berkovic, D.; Wiegmann, K.; Krönke, M. TNF activates NF-kappa B by phosphatidylcholinespecific phospholipase C-induced "acidic" sphingomyelin breakdown. Cell 1992, 71, 765-776. [CrossRef]

5. Wasserstein, M.P.; Desnick, R.J.; Schuchman, E.H.; Hossain, S.; Wallenstein, S.; Lamm, C.; McGovern, M.M. The natural history of type B Niemann-Pick disease: Results from a 10-year longitudinal study. Pediatrics 2004, 114, e672-e677. [CrossRef] [PubMed]

6. McGovern, M.M.; Aron, A.; Brodie, S.E.; Desnick, R.J.; Wasserstein, M.P. Natural history of Type A Niemann-Pick disease: Possible endpoints for therapeutic trials. Neurology 2006, 66, 228-232. [CrossRef]

7. McGovern, M.M.; Dionisi-Vici, C.; Giugliani, R.; Hwu, P.; Lidove, O.; Lukacs, Z.; Mengel, K.E.; Mistry, P.K.; Schuchman, E.H.; Wasserstein, M.P. Consensus recommendation for a diagnostic guideline for acid sphingomyelinase deficiency. Genet. Med. 2017, 19, 967-974. [CrossRef]

8. Deodato, F.; Boenzi, S.; Taurisano, R.; Semeraro, M.; Sacchetti, E.; Carrozzo, R.; Dionisi-Vici, C. The impact of biomarkers analysis in the diagnosis of Niemann-Pick C disease and acid sphingomyelinase deficiency. Clin. Chim. Acta 2018, 486, 387-394. [CrossRef]

9. McGovern, M.M.; Avetisyan, R.; Sanson, B.J.; Lidove, O. Disease manifestations and burden of illness in patients with acid sphingomyelinase deficiency (ASMD). Orphanet J. Rare Dis. 2017, 12, 41. [CrossRef]

10. Kingma, S.D.; Bodamer, O.A.; Wijburg, F.A. Epidemiology and diagnosis of lysosomal storage disorders; challenges of screening Best Pract. Res. Clin. Endocrinol. Metab. 2015, 29, 145-157. [CrossRef]

11. Lidove, O.; Belmatoug, N.; Froissart, R.; Lavigne, C.; Durieu, I.; Mazodier, K.; Serratrice, C.; Douillard, C.; Goizet, C.; Cathebras, P.; et al. Acid sphingomyelinase deficiency (Niemann-Pick B disease) in adulthood: A retrospective multicentre study of 28 adult patients. Rev. Med. Interne 2017, 38, 291-299. [CrossRef]

12. Cassiman, D.; Packman, S.; Bembi, B.; Ben Turkia, H.; Al-Sayed, M.; Schiff, M.; Imrie, J.; Mabe, P.; Takahashi, T.; Mengel, K.E.; et al. Cause of death in patients with chronic visceral and chronic neurovisceral acid sphingomyelinase deficiency (Niemann-Pick disease type B and B variant): Literature review and report of new cases. Mol. Genet. Metab. 2016, 118, 206-213. [CrossRef]

13. Borie, R.; Crestani, B.; Guyard, A.; Lidove, O. Interstitial lung disease in lysosomal storage disorders. Eur. Respir. Rev. 2021, 30, 200363. [CrossRef]

14. McGovern, M.M.; Wasserstein, M.P.; Giugliani, R.; Bembi, B.; Vanier, M.T.; Mengel, E.; Brodie, S.E.; Mendelson, D.; Skloot, G.; Desnick, R.J.; et al. A prospective, cross-sectional survey study of the natural history of Niemann-Pick disease type B. Pediatrics 2008, 122, e341-e349. [CrossRef] [PubMed]

15. Schuchman, E.H.; Desnick, R.J. Types A and B Niemann-Pick disease. Mol. Genet. Metab. 2017, 120, 27-33. [CrossRef] [PubMed]

16. Langeveld, M.; Hollak, C.E.M. Bone health in patients with inborn errors of metabolism. Rev. Endocr. Metab. Disord. 2018, 19, 81-92. [CrossRef]

17. Eskes, E.C.B.; Sjourke, B.; Vaz, F.M.; Goorden, S.M.; van Kuilenburg, A.B.; Aerts, J.; Hollak, C.E. Biochemical and imaging parameters in acid sphingomyelinase deficiency: Potential utility as biomarkers. Mol. Genet. Metab. 2020, 130, 16-26. [CrossRef] [PubMed]

18. McGovern, M.M.; Lippa, N.; Bagiella, E.; Schuchman, E.H.; Desnick, R.J.; Wasserstein, M.P. Morbidity and mortality in type B Niemann-Pick disease. Genet. Med. 2013, 15, 618-623. [CrossRef]

19. Pokrzywinski, R.; Hareendran, A.; Nalysnyk, L.; Cowie, S.; Crowe, J.; Hopkin, J.; Joshi, D.; Pulikottil-Jacob, R. Impact and burden of acid sphingomyelinase deficiency from a patient and caregiver perspective. Sci. Rep. 2021, 11, 20972. [CrossRef]

20. McGovern, M.M.; Pohl-Worgall, T.; Deckelbaum, R.J.; Simpson, W.; Mendelson, D.; Desnick, R.J.; Schuchman, E.H.; Wasserstein, M.P. Lipid abnormalities in children with types A and B Niemann Pick disease. J. Pediatr. 2004, 145, 77-81. [CrossRef]

21. Miranda, S.R.; He, X.; Simonaro, C.M.; Gatt, S.; Dagan, A.; Desnick, R.J.; Schuchman, E.H. Infusion of recombinant human acid sphingomyelinase into niemann-pick disease mice leads to visceral, but not neurological, correction of the pathophysiology. FASEB J. 2000, 14, 1988-1995. [CrossRef] [PubMed]

22. Murray, J.M.; Thompson, A.M.; Vitsky, A.; Hawes, M.; Chuang, W.L.; Pacheco, J.; Wilson, S.; McPherson, J.M.; Thurberg, B.L.; Karey, K.P.; et al. Nonclinical safety assessment of recombinant human acid sphingomyelinase (rhASM) for the treatment of acid sphingomyelinase deficiency: The utility of animal models of disease in the toxicological evaluation of potential therapeutics. Mol. Genet. Metab. 2015, 114, 217-225. [CrossRef] [PubMed]

23. Wasserstein, M.P.; Jones, S.A.; Soran, H.; Diaz, G.A.; Lippa, N.; Thurberg, B.L.; Culm-Merdek, K.; Shamiyeh, E.; Inguilizian, H.; Cox, G.F.; et al. Successful within-patient dose escalation of olipudase alfa in acid sphingomyelinase deficiency. Mol. Genet. Metab. 2015, 116, 88-97. [CrossRef] 
24. Wasserstein, M.; Arash-Kaps, L.; Barbato, A.; Gallagher, R.C.; Giugliani, R.; Guelbert, N.B.; Hollak, C.; Ikezoe, T.; Lachmann, R.; Lidove, O.; et al. Adults with chronic acid sphingomyelinase deficiency show significant visceral, pulmonary, and hematologic improvements after enzyme replacement therapy with olipudase alfa: 1-year results of the ASCEND placebo-controlled trial. Mol. Genet. Metab. 2021, 132, S110. [CrossRef]

25. McGovern, M.M.; Wasserstein, M.P.; Kirmse, B.; Duvall, W.L.; Schiano, T.; Thurberg, B.L.; Richards, S.; Cox, G.F. Novel first-dose adverse drug reactions during a phase I trial of olipudase alfa (recombinant human acid sphingomyelinase) in adults with Niemann-Pick disease type B (acid sphingomyelinase deficiency). Genet. Med. 2016, 18, 34-40. [CrossRef]

26. Wasserstein, M.P.; Diaz, G.A.; Lachmann, R.H.; Jouvin, M.-H.; Nandy, I.; Ji, A.J.; Puga, A.C. Olipudase alfa for treatment of acid sphingomyelinase deficiency (ASMD): Safety and efficacy in adults treated for 30 months. J. Inherit. Metab. Dis. 2018, 41, 829-838. [CrossRef]

27. Diaz, G.A.; Jones, S.A.; Scarpa, M.; Mengel, K.E.; Giugliani, R.; Guffon, N.; Batsu, I.; Fraser, P.A.; Li, J.; Zhang, Q.; et al. One-year results of a clinical trial of olipudase alfa enzyme replacement therapy in pediatric patients with acid sphingomyelinase deficiency. Genet. Med. 2021, 23, 1543-1550. [CrossRef]

28. Thurberg, B.L.; Wasserstein, M.P.; Jones, S.A.; Schiano, T.D.; Cox, G.F.; Puga, A.C. Clearance of hepatic sphingomyelin by olipudase alfa is associated with improvement in lipid profiles in acid sphingomyelinase deficiency. Am. J. Surg. Pathol. 2016, 40, 1232-1242. [CrossRef]

29. Thurberg, B.L.; Diaz, G.A.; Lachmann, R.H.; Schiano, T.; Wasserstein, M.P.; Ji, A.J.; Zaher, A.; Peterschmitt, M.J. Long-term efficacy of olipudase alfa in adults with acid sphingomyelinase deficiency (ASMD): Further clearance of hepatic sphingomyelin is associated with additional improvements in pro- and anti-atherogenic lipid profiles after 42 months of treatment. Mol. Genet. Metab. 2020, 131, 245-252. [CrossRef] [PubMed]

30. Garside, B.; Ho, J.H.; Kwok, S.; Liu, Y.; Dhage, S.; Donn, R.; Iqbal, Z.; Jones, S.A.; Soran, H. Changes in PCSK 9 and apolipoprotein B100 in Niemann-Pick disease after enzyme replacement therapy with olipudase alfa. Orphanet J. Rare Dis. 2021, 16, 107. [CrossRef]

31. Wasserstein, M.; Arash-Kaps, L.; Barbato, A.; Gallagher, R.; Giugliani, R.; Guelbert, N.; Hollak, C.; Ikezoe, T.; Lachmann, R.; Lidove, O.; et al. One-year results of the placebo-controlled ASCEND trial of olipudase alfa enzyme replacement therapy in adults with chronic acid sphingomyelinase deficiency [OP093]. Mol. Genet. Metab. 2021, 132, S64-S65. [CrossRef]

32. Sanofi-Genzyme. Press Release. Sanofi: FDA Grants Breakthrough Therapy Designation for Genzyme's Olipudase Alfa. Available online: https:/ / www.sanofi.com/en/media-room/press-releases/2015/2015-06-04-07-00-00 (accessed on 22 September 2021).

33. European Medicines Agency. EU/3/01/056: Orphan Designation for the Treatment of Niemann-Pick Disease. Available online: https:/ / www.ema.europa.eu/en/medicines/human/orphan-designations/eu301056 (accessed on 21 September 2021).

34. Vanier, M.T. Niemann-Pick diseases. Handb. Clin. Neurol. 2013, 113, 1717-1721.

35. Bell, E.C.; Cox, N.S.; Goh, N.; Glaspole, I.; Westall, G.P.; Watson, A.; Holland, A.E. Oxygen therapy for interstitial lung disease: A systematic review. Eur. Respir. Rev. 2017, 26, 160080. [CrossRef] [PubMed]

36. Dowman, L.; Hill, C.J.; May, A.; Holland, A.E. Pulmonary rehabilitation for interstitial lung disease. Cochrane Database Syst. Rev. 2021, 2, CD006322. [CrossRef] [PubMed]

37. Mauhin, W.; Levade, T.; Vanier, M.T.; Froissart, R.; Lidove, O. Prevalence of cancer in acid sphingomyelinase deficiency. J. Clin. Med. 2021, 10, 5029. [CrossRef]

38. Ordieres-Ortega, L.; Galeano-Valle, F.; Mallén-Pérez, M.; Muñoz-Delgado, C.; Apaza-Chavez, J.E.; Menárguez-Palanca, F.J.; Alvarez-Sala Walther, L.A.; Demelo-Rodríguez, P. Niemann-Pick disease type-B: A unique case report with compound heterozygosity and complicated lipid management. BMC Med. Genet. 2020, 21, 94. [CrossRef] [PubMed]

39. Arenz, C. Small molecule inhibitors of acid sphingomyelinase. Cell Physiol. Biochem. 2010, 26, 1-8. [CrossRef]

40. Bonanni, P.; Grazzini, M.; Niccolai, G.; Paolini, D.; Varone, O.; Bartoloni, A.; Bartalesi, F.; Santini, M.G.; Baretti, S.; Bonito, C.; et al. Recommended vaccinations for asplenic and hyposplenic adult patients. Hum. Vaccin. Imunother. 2017, 13, 359-368. [CrossRef]

41. Lee, G.M. Preventing infections in children and adults with asplenia. Hematol. Am. Soc. Hematol. Educ. Program 2020, 2020, 328-335. [CrossRef]

42. Gao, Y.D.; Ding, M.; Dong, X.; Zhang, J.-J.; Azkur, A.K.; Azkur, D.; Gan, H.; Sun, Y.-L.; Fu, W.; Li, W.; et al. Risk factors for severe and critically ill COVID-19 patients: A review. Allergy 2021, 76, 428-455. [CrossRef]

43. Vanier, M.T. Prenatal diagnosis of Niemann-Pick diseases types A, B and C. Prenat. Diagn. 2002, 22, 630-632. [CrossRef] [PubMed]

44. Wasserstein, M.P.; Schulman, E.H. Acid sphingomyelinase deficiency. In GeneReviews ®; Adam, M.P., Ardinger, H.H., Pagon, R.A., Wallace, S.E., Bean, L.J.H., Mirzaa, G., Amemiya, A., Eds.; University of Washington: Seattle, WA, USA, 2006 ; pp. 1993-2021.

45. Agence Nationale de Sécurité du Médicament et des Produits de Santé (ANSM). Autorisations Temporaires d'Utilisation (ATU). Available online: https:/ / archiveansm.integra.fr/Activites/Autorisations-temporaires-d-utilisation-ATU/Qu-est-ce-qu-uneautorisation-temporaire-d-utilisation/(offset)/1 (accessed on 18 July 2021).

46. Jones, S.A.; McGovern, M.; Lidove, O.; Giugliani, R.; Mistry, P.K.; Dionisi-Vici, C.; Munoz-Rojas, M.V.; Nalysnyk, L.; Schecter, A.D.; Wasserstein, M. Clinical relevance of endpoints in clinical trials for acid sphingomyelinase deficiency enzyme replacement therapy. Mol Genet Metab. 2020, 131, 116-123. [CrossRef] [PubMed] 